\title{
APRENDER DE NUESTRA EXPERIENCIA PARA QUE LA PAZ SÍ LE CUMPLA ESTA VEZ A LOS COLOMBIANOS
}

\section{Learning form previous experience so this time peace become true for colombian people}

\author{
Claudia López \\ Senadora de la República por el Partido Alianza Verde. Contacto: clopez10@senado.gov.co
}

\section{Resumen}

Históricamente el gobierno colombiano ha sido incapaz de construir ciudadanía, Estado y economía de mercado en la totalidad del territorio. Este artículo plantea la importancia del cambio del paradigma de las relaciones centro-regiones, para cumplir con el objetivo de reemplazar a los actores ilegales en el territorio por instituciones sociales, estatales y económicas sólidas y legítimas.

Palabras clave: Ciudadanía - Colombia - Estado - FARC Mercado - Proceso de paz

\section{Abstract}

Historically the Colombian government has failed to promote citizenship, state building and developing a legal market economy, as a way to assure legitimacy in all its territory. In order to achieve this aim, this article considers that Colombian State should focus in changing the paradigm of centre-periphery to be able to replace all the illegal actors that have had control of the territory.

Keywords: Citizenship - Colombia - FARC - Market economy - Peace process - State building

\section{Introducción}

De los más de cincuenta años de duración del conflicto armado, los gobiernos han invertido los últimos treinta en diferentes tipos de estrategias de guerra y paz negociada para desmontar los grupos armados ilegales protagonistas de ese conflicto. Para hacerlo, han combinado descentralización, desmovilización y programas presidenciales para llevar el Estado a las regiones; esa combinación la han usado para lidiar con la presión social y política por democratizar el acceso al poder político y el presupuesto, para someter e incorporar a los grupos armados ilegales que desafían al Estado y para fortalecer la presencia estatal en las regiones. El balance de esas recetas gubernamentales es ampliamente analizado en nuestra investigación que será publicada en el libro ¡Adiós a las Farc!, ¿Y Ahora qué? Construir Ciudadanía, Estado y Mercado para unir las tres Colombias, en el cual se basa el presente artículo.

La evidencia recopilada en esta investigación permite afirmar que en los últimos treinta años Colombia ha construido un Estado y un Gobierno Nacional mucho más fuertes, pero que las precariedades municipales y enormes brechas regionales en capacidad institucional y calidad de vida no se han cerrado, y en muchos casos se han profundizado. Así mismo damos cuenta de que en las regiones en las que se desmovilizan grupos 
armados ilegales nunca se ha hecho un esfuerzo sostenido para reemplazar las formas de control de estos grupos por instituciones sociales y estatales legítimas. Pasada la foto de la desmovilización, el Estado sigue tan ausente o precario como siempre.

En los municipios donde operaban los grupos armados desmovilizados hay impactos más positivos y sostenidos en el tiempo de fortalecimiento de la estatalidad local que en los municipios intervenidos por los programas presidenciales que "llevan el Estado". Sin embargo, en ambos casos los efectos mutan al vaivén de las dinámicas de la confrontación armada, las estrategias gubernamentales para lidiar con ella y las relaciones de poder y clientelismos entre gobernantes y dirigentes locales y nacionales.

Asentar establemente los impactos positivos de la desmovilización y construir ciudadanía, estado y mercado en más de la mitad del país es el reto que tenemos como generación. Tenemos que lograr que en las regiones el Estado asegure el control de la seguridad, justicia y tributación, provea bienes públicos esenciales y se gane una legitimidad duradera en el conjunto de su territorio y para toda su población.

\section{Aprender de nuestra experiencia}

Colombia es el único país del mundo que ha hecho diez procesos de paz y desmovilizaciones colectivas en los últimos treinta años. Aunque las desmovilizaciones han tenido impactos positivos en la estatalidad local, la ausencia de una visión, acciones e inversiones sostenidas dirigidas a construir instituciones estatales y de mercado en las regiones, que ofrezcan alternativas de vida a la población y regulen sus relaciones políticas y económicas, hace que se reciclen grupos armados y violencias en los territorios.

Tras cada proceso de paz, el Estado solo fue a los municipios priorizados por el grupo que se desmovilizó, con centavos y, en el mejor de los casos, por un par de años a cumplir a regañadientes parte de lo pactado. Sin un plan estatal de corto y largo plazo de fortalecimiento de la estatalidad local, no se construyeron instituciones sociales y estatales sólidas que reemplazaron el orden de los armados y la ilegalidad.Como los ilegales que se desmovilizaron no pidieron inversión para fortalecer la estatalidad local — la seguridad, justicia y tributación local- de alcaldías y gobernaciones, en eso no se invirtió.

\begin{tabular}{|c|c|c|c|c|c|}
\hline Grupo desmovilizado & $M-19$ & PRT & EPL & $\begin{array}{l}\text { Quintín } \\
\text { Lame }\end{array}$ & $\begin{array}{l}\text { Corriente de } \\
\text { Renovacion Socialista }\end{array}$ \\
\hline $\begin{array}{l}\text { Número de } \\
\text { desmovilizados }\end{array}$ & 900 & 17 & 87 & 17 & 59 \\
\hline $\begin{array}{l}\text { Municipios priorizados } \\
\text { para inversión }\end{array}$ & 46 & 200 & 2000 & 157 & 433 \\
\hline (en millones de pesos) & 7.049 & 3.233 & 21.555 & 6.467 & 14.877 \\
\hline $\begin{array}{l}\text { Inversión como } \\
\text { \% del PIB }\end{array}$ & $0.00 \%$ & $0,00 \%$ & $0,01 \%$ & $0,00 \%$ & $0,01 \%$ \\
\hline $\begin{array}{l}\text { Superficie de los } \\
\text { municipios } \\
\text { priorizados } \\
\text { (en Km2) }\end{array}$ & 2'732.800 & 505.400 & $7^{\prime} 163.100$ & 926.900 & $2 ' 944.400$ \\
\hline $\begin{array}{l}\text { Población de } \\
\text { municipios } \\
\text { priorizados }\end{array}$ & $14^{\prime} 972.076$ & 421.013 & $19 ' 894.693$ & 771.713 & 21'229.692 \\
\hline
\end{tabular}




\begin{tabular}{|c|c|c|c|c|}
\hline Programa de paz & $\begin{array}{l}\text { Plan Nacional } \\
\text { de Rehabilitación } \\
1983-1992\end{array}$ & $\begin{array}{l}\text { Plan Colombia } \\
\text { Militar } \\
2000-2008\end{array}$ & $\begin{array}{l}\text { Plan Colombia } \\
\text { Social } \\
2004-2010\end{array}$ & \multirow[b]{2}{*}{$\begin{array}{l}\text { * No existe un listado consolidado ni detallado de } \\
\text { municipios intevenenidos por el Plan Colombio, } \\
\text { ni en su componente social ni en el militar. }\end{array}$} \\
\hline $\begin{array}{l}\text { Municipios priorizados } \\
\text { para Inversion }\end{array}$ & 346 & & 66 & \\
\hline $\begin{array}{c}\text { Inversión } \\
\text { (en millones de pesos) }\end{array}$ & $5^{\prime} 572.690$ & $20 \prime 000.000$ & 1'984'484 & \multirow{2}{*}{$\begin{array}{l}\text { ** El volumen de población varía sustancialmente } \\
\text { por processo según la variación de municipios } \\
\text { y ciudades capitales incluidas. }\end{array}$} \\
\hline $\begin{array}{l}\text { Inversión } \\
\text { como\% del'PIB }\end{array}$ & $0,50 \%$ & $1,20 \%$ & $0,30 \%$ & \\
\hline $\begin{array}{l}\text { Superficie de } \\
\text { los municipios } \\
\text { priorizados } \\
\text { (en Km2) }\end{array}$ & $55^{\prime} 455.600$ & & $15^{\prime} 784.200$ & \multirow{2}{*}{ 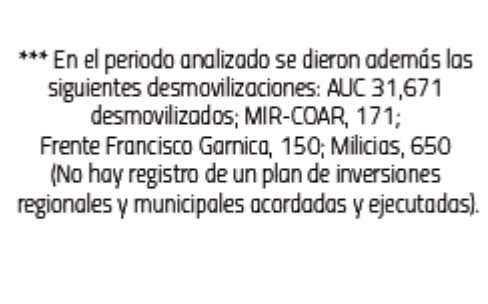 } \\
\hline $\begin{array}{l}\text { Población de los } \\
\text { municipios } \\
\text { priorizados }\end{array}$ & 8'766.944 & & $3^{\prime} 085.224$ & \\
\hline
\end{tabular}

Fuente: ¡Adiós a las Farc!, ¿Y Ahora qué? Construir Ciudadanía, Estado y Mercado para unir las tres Colombias.

Solo se hizo "inversión social" para las comunidades y los desmovilizados, así como en algunas obras de infraestructura. Tampoco se renunció a la combinación de formas de lucha estatal, clientelismo, corrupción, violencia política y delegación estatal a agentes politiqueros y criminalizados.

El balance de la política de descentralizar, pacificar e intervenir es agridulce, pues no resultó una herramienta eficaz para construir ciudadanía, Estado y mercado legal y legítimo a nivel local. Los resultados demuestran que ese repertorio no ha logrado construir a lo largo del país municipios institucionalmente fuertes, económicamente viables y socialmente prósperos.

La pacificación e intervención nacional, como la hemos conocido y ejecutado en estos últimos treinta años, llegó a su techo de rendimientos en términos de construir capacidades institucionales a nivel local. Es decir, hacer más de lo mismo o girar más recursos, con la descentralización actual, no va a fortalecer las capacidades sociales e institucionales locales para que las comunidades, alcaldías y gobernaciones sean realmente la representación del Estado en los territorios. Si queremos resultados diferentes vamos a tener que intentar recetas diferentes.

\section{Comprender el desafío y ensayar recetas diferentes}

La geografía, la herencia colonial y la formación y operación del régimen político han provocado -y el conflicto armado y el narcotráfico lo han profundizado- la presencia diferenciada del Estado en las regiones, y construido formas de connivencia endógenas entre presencia diferenciada del Estado y presencia diferenciada de los grupos armados al margen de la ley.

Si algo podemos aprender de estos treinta años, es que es necesario romper eficazmente con tres círculos viciosos que vinculan la relación de las élites centrales y regionales con la precariedad estatal regional:

1. Las alianzas de quienes posan de estadistas en Bogotá mientras se eligen y co-gobiernan con políticos corruptos y criminalizados en las regiones.

2. La evasión del pago y redistribución de impuestos e inversión pública, necesarias para construir Estado en las regiones, mientras se tolera la enorme corrupción (¡la tal mermelada!) que hace "fluir" las relaciones entre el presidente, el Congreso y la clase política local. 
3. Reemplazar a los competidores armados que se desmovilizan y romper la distribución de funciones de facto que durante años ha existido en el territorio entre el Estado y sus competidores armados (el Estado hace inversión social mientras los grupos armados ilegales prestan seguridad, justicia privada, y recaudan impuestos por medio de la extorsión).

Superar esa enorme presencia diferenciada y endógena supone entender que el Estado es un orden social e institucional, que se construye a partir de las demandas políticas que los ciudadanos logren hacer valer en el debate público y electoral a sus gobernantes, y a partir de la economía y política de cada región. Por eso, el Estado no se puede "llevar a las regiones" desconociendo o sometiendo las demandas de la población y sus formas locales de organización, poder y representación.

Superar ese fenómeno de presencia estatal diferenciada y su correlato de presencia y control de grupos armados ilegales supone ser eficaces en cinco propósitos fundamentales:

1. Cambiar la forma de operación del régimen político, acabar con la clase política clientelista y la manera en que se relacionan y construyen gobernabilidad las élites políticas regionales y las centrales, que inhibe e impide el funcionamiento eficaz y democrático del Estado en las regiones y en el nivel central.

2. Desmovilizar a todos los poderes armados de facto que usurpan, ejercen o inhiben la presencia y el adecuado funcionamiento del Estado en las regiones.

3. Reconocer e incorporar las legítimas demandas sociales, políticas y económicas de los 15 millones de colombianos, en su mayoría rurales, que han vivido bajo el control de esos poderes de facto.

4. Reemplazar el orden de facto de los poderes locales ilegales por instituciones sociales y estatales sólidas y legítimas, que sean reguladoras del orden territorial, social, político y económico, y sirvan como articuladoras de la relación regiones-Estado.

5. Superar la subespecificación de los derechos de propiedad y las fuentes ilegales de ingreso, por derechos de propiedad y relaciones de mercado bien especificadas, protegidas y reguladas, en ofertas económicas legales y diversificadas.

6. Profundizar y fortalecer la descentralización fiscal y administrativa, construyendo las capacidades para que las Alcaldías y Gobernaciones sean realmente el Estado en el territorio y garanticen los derechos de los ciudadanos.

Lo anterior solo es posible si se fortalece a la ciudadanía y a la sociedad civil local y regional para que pueda actuar como agente reformador de la clase política y poderes de facto locales y regionales; como agente constructor de las instituciones locales que los reemplacen, y como actor político capaz de hacer valer sus derechos y cumplir sus deberes constitucionales.

\section{¿Dónde y en qué enfocarse para construir paz territorial?}

Aunque es cierto que la paz implica reformas e inversiones de alcance nacional, también es cierto que así como no todas las regiones y los municipios han estado igualmente expuestos al conflicto armado, no todos los municipios y regiones pueden estar igualmente priorizados en el posconflicto.

Por eso se requiere, a la par de una visión global y nacional de paz que involucre al conjunto de la sociedad, de reformas estructurales; también de una acción focalizada sobre los factores y territorios que pueden impedir que se concrete la efectiva desmovilización de las Farc y el Eln, que ponga en riesgo la seguridad de las comunidades y los desmovilizados, y que impida la reproducción o reciclaje de dinámicas de ocupación y explotación ilegal del territorio.

Así mismo, se requiere una visión de más largo plazo para reemplazar los órdenes y regulaciones de facto de los oligopolios armados por instituciones sociales y estatales que ofrezcan oportunidades de inclusión, representación y movilidad a los colombianos que han vivido $\sin$ Estado.

¿En dónde debemos centrarnos? ¿Cuáles municipios debemos priorizar? ¿En dónde debemos construir ciudadanía, Estado y mercado? Para identificar los municipios sujetos de intervención en el posconflicto usamos cinco criterios: 
(1) municipios con presencia de Farc; (2) municipios con presencia de competidores armados que van a tratar de apostar a la inercia de expansión del control ilegal territorial (Eln y Bacrim); (3) municipios donde se concentran tres tipos de economías ilegales: cultivos de coca, rutas de narcotráfico y minería criminal; (4) municipios con alta exclusión por alta ruralidad y bajo desarrollo humano; (5) municipios con precario desempeño estatal por baja eficacia de la justicia, alta impunidad en homicidios y bajo desempeño fiscal y administrativo del gobierno local; (6) municipios donde residan las víctimas del conflicto armado, a quienes hay que asegurarles sus derechos, con o sin acuerdos de paz.

Del cruce de estas 6 variables logramos identificar 455 municipios que requieren ser priorizados para acciones e inversiones en el posconflicto.

\section{Municipios priorizados para la paz territorial y criterios de priorización}

El desafío no es menor: estos 455 municipios representan el $41 \%$ de los municipios del país, su población asciende a los 15,7 millones de habitantes y concentran el $77 \%$ de las víctimas. 388 de estos son rurales (ver mapa 1), según la definición de la Misión Para la Transformación del Campo.

En los 455 municipios se debe intervenir prioritariamente para reemplazar los órdenes derivados de la competencia armada ilegal por control territorial, por instituciones de ciudadanía, Estado y mercado legal. Estos requieren una inversión adicional y sostenida por 15 años para lograr el fortalecimiento institucional en seguridad, justicia, tributación, provisión de bienes públicos, infraestructura, integración y desarrollo social y económico incluyente y sostenible, que les permitan fortalecerse significativamente y cerrar las brechas actuales.

Las inversiones propuestas están pensadas y alineadas para lograr tres propósitos que se ha trazado el país en compromisos nacionales e internacionales y que debemos alcanzar como generación de la paz entre 2016 y 2030:

1. Cumplir con las metas, inversiones y recomendaciones de la Misión de Transformación del Campo y Desarrollo Rural.
2. Cumplir las metas de los Objetivos de Desarrollo Sostenible.

3. Construir una paz territorial estable y duradera.

Para lograr esos tres propósitos estimamos que, en los próximos 15 años, Colombia debe invertir en promedio $1,6 \%$ del PIB adicional por año (333,5 billones en total durante los 15 años) para consolidar la paz territorial en los 455 municipios priorizados y en el conjunto del país, sobre la base de construir ciudadanía, estado y economía de mercado modernas e incluyentes en las regiones, y así saldar la enorme deuda de abandono e inmovilidad social con la Colombia rural y las víctimas del conflicto armado.

\begin{tabular}{|c|c|c|}
\hline Eje de inversiones 2016 - 2030 & $\begin{array}{l}\text { Inverslón } \\
\text { (en billones } \\
\text { de pesos) }\end{array}$ & Porcentaje \\
\hline 1. Construcclón de cludadanía & 169 & $50,7 \%$ \\
\hline 1.1 Participación y organización ciudadana & 2,5 & $0,7 \%$ \\
\hline 1.2 Equidad social & 166,5 & $49,9 \%$ \\
\hline Primera infancia y educación & 126,5 & $37,9 \%$ \\
\hline Salud y saneamiento & 22,1 & $6,6 \%$ \\
\hline Vivienda rural & 13,7 & $4,1 \%$ \\
\hline Otros & 4,2 & $1,3 \%$ \\
\hline 2. Construlr Estado & 21,3 & $6,4 \%$ \\
\hline 2.1 Sistema de justicia rural & 10,6 & $3,2 \%$ \\
\hline $\begin{array}{l}2.2 \text { Regulación de la propiedad, uso y } \\
\text { explotación de la tierra }\end{array}$ & 1,0 & $0,3 \%$ \\
\hline 2.3 Fortalecimiento de tecnocracias locales & 2,0 & $0,6 \%$ \\
\hline 2.4 Justicia y seguridad pública & 7,7 & $2,3 \%$ \\
\hline 3. Construlr Mercado & 95,9 & $28,8 \%$ \\
\hline $\begin{array}{l}3.1 \text { Cambiar la economía polititca: inversión } \\
\text { regional transparentey regalías ambientales }\end{array}$ & 6,5 & $1,9 \%$ \\
\hline $\begin{array}{l}\text { 3.2 Equidad territorial: infraestructura para } \\
\text { el desarrollo incluyente y sostenible }\end{array}$ & 89,4 & $26,8 \%$ \\
\hline 4. Otros acuerdos derlvados de La Habana & 9,7 & $2,9 \%$ \\
\hline 5. Reparadón de las víctlmas & 34,3 & $10,3 \%$ \\
\hline 6. Paz política y electoral & 3,3 & $1 \%$ \\
\hline Total general & 333,5 & $100 \%$ \\
\hline
\end{tabular}

Fuente: ¡Adiós a las Farc!, ¿Y Ahora qué? Construir Ciudadanía, Estado y Mercado para unir las tres Colombias. 
El 85,8 \% del total de esa inversión es para construir ciudadanía, Estado y mercado, que es un mandato de la Constitución para proteger la honra, vida y bienes de los ciudadanos, garantizar sus derechos e incentivar el cumplimiento de sus deberes, lo cual tendría que hacerse con o sin acuerdos de paz.

Un 10,3\% del total de la inversión será para cumplir lo dispuesto en la Ley de víctimas y restitución de tierras, a los cerca de siete millones de víctimas que ha dejado el conflicto armado, compromiso que asumió el país desde 2011, al margen de los acuerdos de paz.

Un 3\% corresponde a las acciones que las Farc solicitan, o porque son los costos directamente relacionados con su desarme y desmovilización, y el 1\% de la inversión se requiere para llevar a cabo las reformas político-electorales que hagan más transparente la competencia electoral local y nacional.

En conclusión, hacer la paz con las Farc cuesta 4 de cada 100 pesos, cumplirle a las víctimas 10 de cada 100 pesos y revitalizar el país 86 de cada 100 pesos. Esas son las proporciones financieras de la paz territorial.

\section{Conclusiones}

La principal condición para un posconflicto exitoso es, no solo desmovilizar, sino reemplazar, con instituciones sociales y públicas en los territorios, las formas de regulación y control de facto que han construido los grupos armados al margen de la ley y nuestro centrismo represivo y delegatario.

El Estado no se lleva a las regiones. Se construye en las regiones a partir de esfuerzos diferenciados con la población y en las condiciones de cada ente territorial. La presencia diferenciada del Estado en Colombia en las últimas décadas ha originado que alli, donde el Estado brilla por su ausencia, poderes de facto asuman los roles, las obligaciones y las competencias que debería ejecutar el Estado.

Debemos saldar la enorme deuda humana y social que tenemos con aproximadamente quince millones de colombianos, abandonados a su suerte, atrapados entre la pobreza e inmovilidad. Esto demanda una inversión grande y un compromiso ético y político aún mayor, pues esos colombianos no tienen cómo imponer con su voto esa prioridad a las mayorías de la Colombia urbana. Somos nosotros los que tenemos que auto imponernos esa obligación con ellos.

Aproximadamente cada cincuenta años una generación de colombianos ha tenido la oportunidad de decidir cómo acabar una guerra de larga duración y cómo construir instituciones para un país moderno, incluyente y en paz. Primero les tocó a quienes vivieron el fin de la Guerra de los Mil Días a inicios del siglo XX, y luego a quienes padecieron la violencia bipartidista a mediados del mismo siglo. Ahora es nuestro turno.

Si aprendemos de nuestra propia experiencia, esta generación pasará a la historia como la que puso fin al último conflicto armado de todo el hemisferio occidental y logró que dejáramos de ser tres países que se desconocen y recelan, y seamos por fin una sola Colombia.

\section{¿Cómo invertir los 86 pesos de cada 100 para que la paz le cumpla a los colombianos?}

\$7 para asegurar la construcción de Estado a nivel municipal, que administre los sistemas de seguridad y justicia, planeación, hacienda e inversión pública.

\$1 para formación, organización, empoderamiento y movilización de las comunidades y sus organizaciones, de manera que puedan hacer el control político.

\$1 para implementar las reformas político-electorales como la biometría, el voto electrónico, y la meritocracia en los organismos de control.

\$49 para garantizar el acceso a bienes públicos fundamentales, tener calidad de vida y ciudadanía: salud, atención integral de primera infancia, educación, agua potable, saneamiento y electricidad, vivienda digna y atención al adulto mayor.

\$28 para construir una economía de mercado incluyente y regulada. Es decir, para proveer la infraestructura, servicios y asistencia técnica que se necesitan para ofrecer oportunidades de inversión e ingresos legales, y así grantizar la sostenibilidad ambiental y territorial. 